\title{
Raoul Baziomo
}

\section{La Famille de Saül dans le conflit Saül versus David}

\section{Étude de la construction narrative des personnages de Jonathan, Mérav et Mikal}

[Die Familie des Saul im Konflikt zwischen Saul und David. Eine Studie zur Erzählkonstruktion der Figuren des Jonatan, der Merab und der Michal.]

RAOUL BAZIOMO

La Famille de Saül dans le conflit

Saül versus David

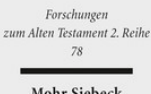

2015. XIII, 301 Seiten. FAT II 78

ISBN 978-3-16-153683-0

DOI 10.1628/978-3-16-153683-0

eBook PDF 109,00€

ISBN 978-3-16-153682-3

fadengeheftete Broschur 109,00€
Veröffentlicht auf Französisch.

Une bonne partie du premier livre de Samuel et le début du second racontent comment et pourquoi est intervenu le transfert de la royauté de Saül à David et à sa maison. Les événements relatés à ce sujet sont situés dans le contexte d'un conflit que Saül ouvre, lorsqu'il réalise que David représente une menace pour son trône. Raoul Baziomo investigue les rôles incarnés par les enfants de Saül et il éclaire sous un angle inédit le récit de l'opposition entre Saül et David, de manière à mettre davantage en lumière le message qu'il porte et le système de valeurs qu'il promeut. Cela fait ressortir également la stratégie narrative déployée par le récit pour amener le lecteur à adhérer à ses valeurs ou le transformer au plan cognitif.

In mehr als der Hälfte des ersten Buchs Samuel und am Anfang des zweiten geht es darum, wie und warum die königliche Herrschaft von Saul an David und dessen Geschlecht ging. Raoul Baziomo untersucht die Rolle, die Sauls Kinder dabei spielten und beleuchtet die Erzählung des Konflikts zwischen Saul und David, um dadurch die Botschaft, die sie übermittelt, und das Wertesystem, das sie vertritt, hervorzuheben

Raoul Baziomo Keine aktuellen Daten verfügbar.

Jetzt bestellen:

https://mohrsiebeck.com/buch/la-famille-de-sauel-dans-le-conflit-sauel-versus-david-9783161536830?no cache=1 order@mohrsiebeck.com

Telefon: +49 (0)7071-923-17

Telefax: +49 (0)7071-51104 